\title{
AGE AND GROWTH IN PHOCOENA PHOCOEN $A$ LINNAEUS, 1758 (CETACEA, ODONTOCETI) FROM THE NORTH SEA
}

\author{
by \\ W. L. VAN UTRECHT \\ Institute of Taxonomic Zoology, University of Amsterdam, The Netherlands
}

\begin{abstract}
Data and material are collected from 106 Harbour Porpoises ( $P$. phocoena) from the southern part of the North Sea. All animals are accidentally caught or found stranded. The greatest length for males in the sample is $151 \mathrm{~cm}$, for females $186 \mathrm{~cm}$. For detailed analysis of body measurements, 30 males and 37 females are selected, while from 20 males and 34 females teeth are used for age analysis. The analysis of the body measurements shows sexual dimorphism in the anterior and posterior part of the back, in the flukes and flippers and in the position of the genital slit. The maximum number of dentinal layers found in the teeth is 12. Males attain sexual maturity after the deposition of $s$ dentinal layers, females when 6 layers are formed, at a body length of about $135 \mathrm{~cm}$ and $150 \mathrm{~cm}$, respectively. Some evidence is found that the population of $P$. phocoena from the North Sea has a lower growth rate than the population from Canadian waters. The gestation period is estimated to be eleven months, the peak of the birth period being in June. The animals are born at a length varying between $67 \mathrm{~cm}$ to $80 \mathrm{~cm}$. Growth of the visceral organs is isogonic. The mean weight of the organs is greater in females than in males.
\end{abstract}

\section{INTRODUCTION}

Though Phocoena phocoena Linnaeus, 1758, the Harbour Porpoise, is a common inhabitant of shallow coastal waters and estuaries of rivers, studies on this species with respect to age and growth are scarce. Bryden (1972) and Mitchell (1975) pointed to the lack of data about this species.

Gaskin \& Blair (1977) reported on age determination by means of the teeth of $P$. phocoena from the western North Atlantic, while MøhlHansen (1954) analysed the available data about length, sex and pregnancy of animals caught for commercial purpose during World War II in the Baltic area. He also studied preserved foetal material obtained at the time. Slijper (1962) reported on the growth and reproduction in $P$. phocoena. His results were based on a relatively small number of animals, from which the ages were not known.
Van Utrecht (1960) compared data of eleven animals from the Baltic area with those of 19 individuals from the North Sea, and later described the difference in length of the "primary" or "neonatal" line in the dentine of the teeth of males and females of $P$. phocoena and a number of other species of odontocetes from the North Sea (Van Utrecht, 1969). His data were confirmed by Nielsen (1972) in her study on age and growth in $P$. phocoena from the Baltic area. Such sexual dimorphism has up to now neither been found in the teeth of Stenella sp. from eastern Pacific waters nor in the teeth of $P$. phocoena from Canadian waters.

Van Deinse has collected data concerning the occurrence of $P$. phocoena along the Dutch coasts, based on strandings during the period 1943-1965. The decline in numbers of this species is clear when pre- and post-war data are compared (see Verwey, 1975). After World War II the decline continued and after 1962 animals became available for examination and dissection only incidentally. Moreover, after 1960, the number of animals in the North Sea became so small that it was not economic anymore to collect them by active hunting. As during the last few years the number of animals brought in for examination further reduced, it is justified now to analyse the material. One has to keep in mind that the animals used for the present study are only part of the total number that was collected, because certain animals were in poor condition upon arrival or were examined elsewhere.

\section{MATERIAL}

Since 1955, Harbour Porpoises caught in trawl nets in the southern part of the North Sea as well 
as animals washed ashore were dissected. The number of animals examined is only a fraction of the total number of strandings and catches recorded by Van Utrecht \& Husson (1968), Husson \& Van Bree (1972), Van Bree \& Husson (1974) and Husson \& Van Bree (1976). Out of 106 animals, 30 males and 37 females were selected, viz. specimens from which complete lists of detailed measurements, and weights of tissues and visceral organs were available. The teeth of 20 males and 34 females were studied for age determination. The skeletons of most of the animals examined are deposited in the collections of the Institute of Taxonomic Zoology (Zoölogisch Museum) of the University of Amsterdam.

The animals used in the present study were all received in fresh or frozen condition. In most cases they were kept frozen until time permitted dissection. Date and position of the catch or stranding were recorded as well as the total length, weight and sex. Preceding the autopsy a series of morphometric data was taken. These were:

L: total length, measured in a straight line from tip of snout to notch of flukes;

a : tip mandible - corner of mouth;

b : tip mandible - centre of eye;

c : centre of eye - orifice of external auditory meatus;

$\mathrm{d}$ : centre of eye - anterior end of basis of flipper;

e : length basis of flipper;

$f$ : length of flipper (from middle of basis to tip);

$g$ : greatest width of flipper;

$\mathrm{h}$ : basis mellon - blowhole;

i : blowhole - anterior end of basis of dorsal fin;

$j$ : length of basis of dorsal fin;

$k$ : height of dorsal fin;

1 : posterior end of basis of dorsal fin - notch of flukes;

$\mathrm{m}$ : tip mandible - umbilicus;

n : umbilicus - anterior end of genital slit;

o: length of genital slit;

p : posterior end of genital slit - anus;

$q$ : anus - notch of flukes;

$r$ : span of flukes.

All measurements, except the total length, are taken along the body contour. The measurements $\mathrm{d}$ and $\mathrm{e}$ are not included in the analysis. The measurements $h, i, j$ and $n, o, p, q$ are used separately and combined. Those first mentioned represent the distance between the tip of the snout and the posterior end of the basis of the dorsal fin, the second group gives the distance between the umbilicus and the notch of the flukes. When possible a tooth was taken from the middle of the mandibula. As far as possible, the ovaries of females were preserved for histological examination.

Initially the teeth were ground by hand to longitudinal axial sections. This direction, instead of a cross section, was chosen to be sure that all dentinal layers were included in the counts. Later, an electric driven low speed diamond circular saw was used. The teeth were then embedded in plastic resin, in order to facilitate handling and to assure the right orientation of their axis to the saw. The sections, about $120 \mu \mathrm{m}$ thick, were mounted on glass slides in plastic resin. This procedure was not only less time consuming, but the sections proved also to be of equal or even better quality than those ground by hand. The sections were examined under transmitted and under polarized light.

\section{RESULTS}

The animals used for the present study were collected over a period of about 20 years, from a declining population. So one can hardly expect them to be a representative sample of the population of $P$. phocoena from the North Sea. Moreover, all animals were caught by accident or were found washed ashore. One can be fairly certain that a Harbour Porpoise in healthy condition can easily avoid trawl nets. As the animals are completely adapted to, and well acquainted with, life in very shallow and often turbulent waters, stranding of healthy individuals is also not very likely.

\section{Growth}

In the present material the greatest length recorded for males was $151 \mathrm{~cm}$, and for females $186 \mathrm{~cm}$. Measurements of the various parts of the body are given as percentages of the total length. The calculations include only animals from $100 \mathrm{~cm}$ and above.

In fig. 1 the distance between the tip of the snout and the posterior end of the basis of the dorsal fin is given, and also the distance between the latter point and the notch of the flukes, for males. The regression line of measurements of the anterior part of the dorsum is represented by the formula:

$Y=-0.125 X+79.535(r=-0.459, N=28, P<0.02)$. 
For the posterior part of the dorsum of males the equation is:

$Y=0.0505 X+30.877(r=0.576, N=28, P<0.01)$. In males growth of the anterior part of the dorsum is negatively heterogonic, while it is positively heterogonic in the posterior part. There is a significant decrease in the proportion of the anterior part of the dorsum, from $67 \%$ to $61 \%$, while there is a significant increase from about $40 \%$ to $44 \%$ in the posterior part. The calculations show that in females growth is isogonic in the anterior and posterior parts of the dorsum. The anterior part of the dorsum comprises here about $62 \%$ of the total length (mean $=61.92$, var. $=$ 6.28, S.D. $=2.51, N=35$ ). In the posterior part this is about $42 \%$ (mean $=42.25$, var. $=4.01$, S.D. $=2.00, N=37$ ). These figures demonstrate a difference between males and females of $P$. phocoena in proportion and growth of the anterior and posterior parts of the dorsum.

Along the ventral side of the animals, the distance between the tip of the mandible and the umbilicus, and between this point and the notch of the flukes is measured. For males (fig. 1) the regression line for the distance between the tip of the mandible and the umbilicus is expressed by the relationship:

$Y=-0.662 X+48.701(r=-0.461, N=21, P<0.05)$. Growth in this part is negatively heterogonic. In females (fig. 2) the regression line for this part can be expressed as:

$Y=-0.063 X+49.190(r=-0.523, N=26, P<0.01)$. Here growth of the anterior part of the ventral side is negatively heterogonic as well. The distance between the tip of the mandible and the umbilicus in males shows a significant decrease in proportion from $42.5 \%$ to $39.5 \%$. In females this decrease is from $42.5 \%$ to $38.7 \%$. In males and females growth of the part of the ventral side between the umbilicus and the notch of the flukes is, according to the calculations, isogonic. In males this part comprises $60 \%$ of the total length (mean $=59.89$, var. $=2.19$, S.D. $=1.48, N=21)$. In females the length of this part is about $59 \%$ of the total length $($ mean $=59.13$, var. $=13.85$, S.D. $=$ $3.72, N=26$ ). These results are in remarkable contrast to those found for the dorsal side of the animals.
As more points of reference are available, smaller parts can be measured along the lateral side of the head and the ventral side of the body. On the lateral side of the head the measurements of the distance between the tip of the mandible and the centre of the eye in males (fig. 1) results in a regression line with the equation:

$Y=-0.056 X+19.410(r=-0.772, N=28, P<0.001)$. So growth in this part is negatively heterogonic. In females (fig. 2) the equation for the corresponding regression line is:

$Y=-0.055 X+19.587(r=-0.868, N=36, P<0.001)$, demonstrating negatively heterogonic growth. In males and females of $P$. phocoena there is a significant decrease of the distance between the tip of the mandible and the centre of the eye. In males this decrease ranges from $13.8 \%$ to $11.1 \%$, in females from $14.1 \%$ to $10.4 \%$ of the total length.

Measurements of the distance between the centre of the eye and the orifice of the external auditory meatus in males results in a line with the equation:

$Y=-0.017 X+6.548(r=-0.507, N=22, P<0.02)$, so the growth of this part is negatively heterogonic. For females the calculations show isogonic growth in this part. In males there is a small, but significant decrease in the distance between the centre of the eye and the orifice of the external auditory meatus, viz. from $4.8 \%$ to $3.97 \%$ of the total length $($ mean $=4.28$, var. $=0.21$, S.D. $=$ $0.46)$. In females there is also a small, however nonsignificant, decrease in proportion, from about $5 \%$ to about $4 \%$ (mean $=4.58$, var. $=0.70$, S.D. $=0.835, N=25$ ). This difference between males and females is most probably caused by the small size of the sample in relation to the greater range of body lengths in females. This idea is supported by the fact that in both cases the spread in the measurements is small.

The part of the head between the tip of the mandible and the corner of the mouth grows negatively heterogonic in $P$. phocoena. In males the equation for the calculated line is:

$Y=-0.027 X+11.360(r=-0.539, N=23, P<0.001)$. There is a significant decrease of about $1 \%$, from about $8 \%$ to about $7 \%$ of the total length. For females the corresponding equation is:

$Y=-0.039 X+13.163(r=-0.757, N=31, P<0.001)$. 


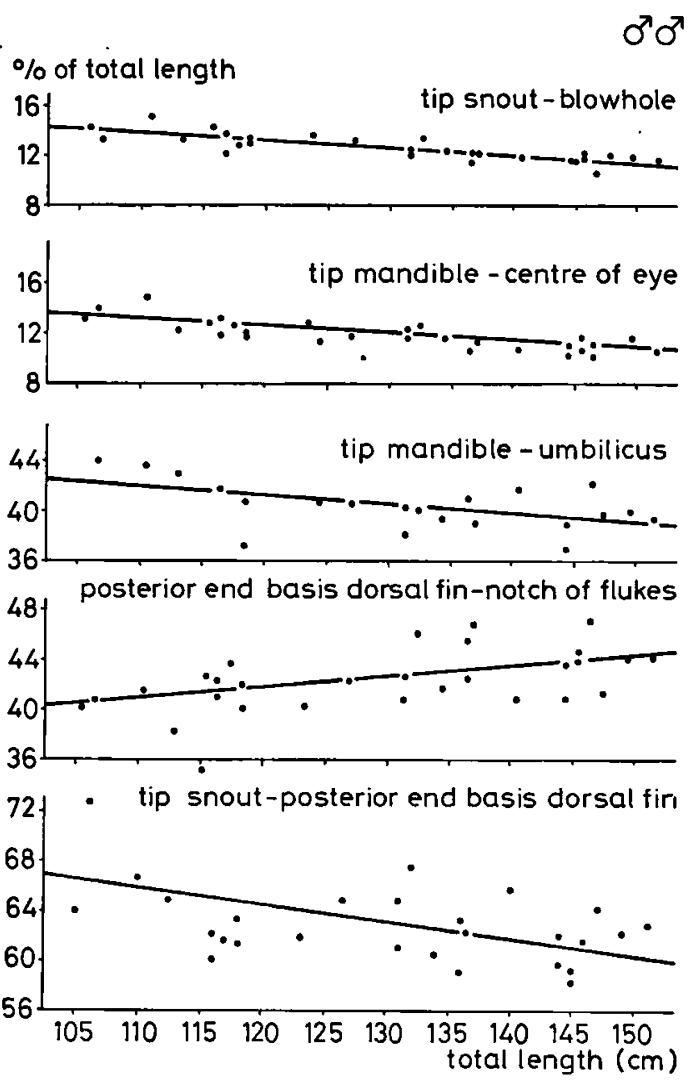

Fig. 1. Growth of various parts of the body of males of $P$. phocoena.

Here the decrease is about $2 \%$, from $9 \%$ to $7 \%$ of the total length.

According to the calculations, the growth of the part of the body between the blowhole and the anterior end of the basis of the dorsal fin is isogonic in both sexes. However, in males there is a decrease in proportion of this part of about $2 \%$, from $36 \%$ to $34 \%$ of the total length (mean = 34.53 , var. $=8.97$, S.D. $=2.995, N=29$ ) . In females there is an increase in proportion of this part of about $2 \%$, from $32 \%$ to $34 \%$ of the total length $($ mean $=33.80$, var. $=2.95$, S.D. $=1.72$, $N=35$ ).

The measurements of the distance between the tip of the snout, which coincides in $P$. phocoena with the basis of the melon, and the blowhole are shown in fig. 1 for males and in fig. 2 for females. The equation for the regression line for males is: $Y=-0.052 X+19.528(r=-0.792, N=28, P<0.001)$, and for females:
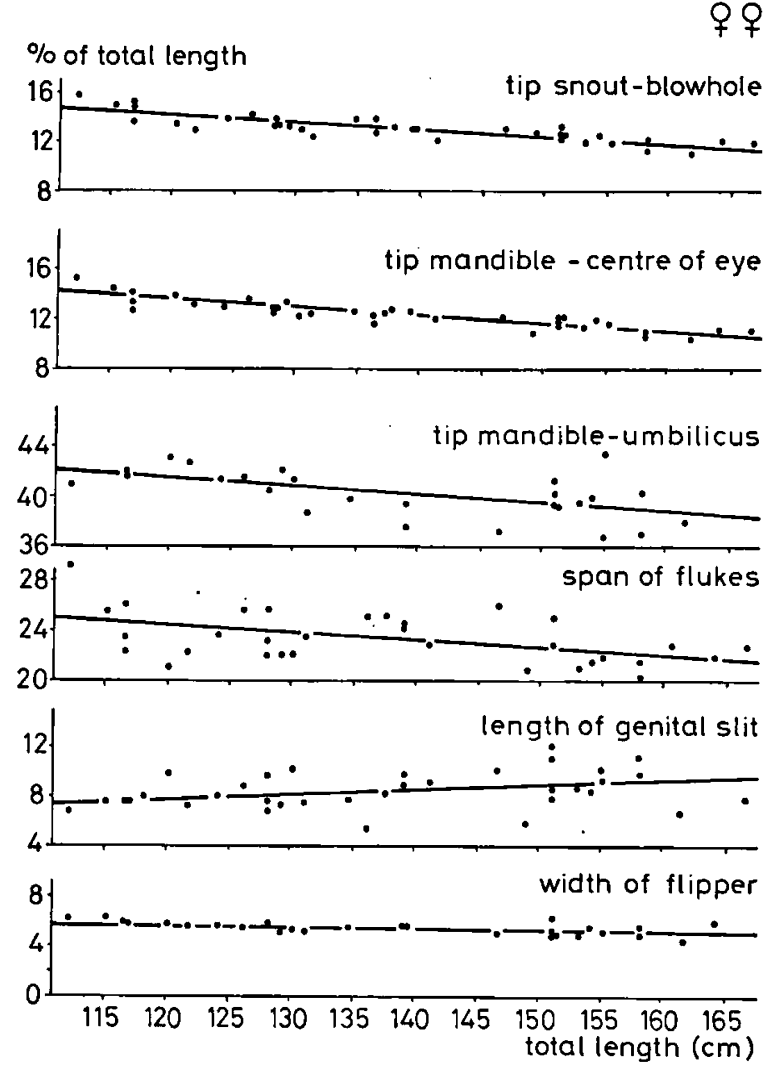

Fig. 2. Growth of various parts of the body of females of P. phocoena.

$Y=-0.050 X+19.844(r=-0.806, N=36, P<0.001)$. In both sexes the growth in this part of the head is negatively heterogonic, there is a decrease in proportion from $14 \%$ to $12 \%$.

There is a considerable difference between males and females in the distance between the umbilicus and the anterior end of the genital slit. Growth in this part of the ventral side proves to be isogonic. In males the distance is about $3.5 \%$ of the total length (mean $=3.41$, var. $=0.49$, S.D. $=0.70, N=22$ ). In females this distance is about $20 \%$ of the total length (mean $=19.82$, var. $=6.56$, S.D. $=2.56, N=26$ ).

According to the calculations, the growth in length of the genital slit in males is isogonic at a level of about $7 \%$ of the total length (mean = 7.24 , var. $=1.97$, S.D. $=1.40, N=30$ ). In females the growth of the genital slit proves to be positively heterogonic with an increase in length from about $7.5 \%$ to $9.6 \%$ of the total length. The 
equation for the regression line (fig. 2 ) is: $Y=0.035 X+3.662(r=0.366, N=35, P<0.05)$.

The distance between the posterior end of the genital slit and the anus was measured in males only, because in females the anus is in contact with the genital slit. Calculations show that the growth of this part in males is isogonic at a level of about $18 \%$ of the total length $($ mean $=18.87$, var. $=$ 3.04, S.D. $=1.74, N=30)$.

The growth of the part of the ventral side between the anus and the notch of the flukes proves to be isogonic in males and females, at a level of about $30 \%$ of the total length. For males the mean is 30.03 (var. $=2.36$, S.D. $=1.54, N=29$ ), and for females the mean is 30.74 (var. $=2.04$, S.D. $=1.43, N=36$ ).

The calculations show that the growth of the span of the flukes in males is isogonic at a level of about $23 \%$ of the total length (mean $=23.25$, var. $=5.40$, S.D. $=2.32, N=28$ ). In females the growth of the span proves to be negatively heterogonic. The equation for the regression line is:

$Y=-0.047 X+29.684(r=-0.392, N=32, P<0.05)$.

There is a decrease from about $24.5 \%$ to $21.8 \%$ of the total length (fig. 2).

The growth in length of the flippers in males of $P$. phocoena and also the growth in width proves to be isogonic. The length is about $14 \%$ of the total length $($ mean $=13.92$, var. $=2.65$, S.D. $=$ $1.63, N=28$ ). The width of the flippers in males varies between 5 and $6 \%$ of the total length $($ mean $=5.49$, var. $=0.28$, S.D. $=0.53, N=$ 22). In females the growth in length of the flippers also proves to be isogonic at a level of about $14 \%$ of the total length (mean $=14.4$, var. $=3.84$, S.D. $=1.96, N=34$ ). The calculations revealed that the growth in width is negatively heterogonic in females. The equation for the regression line (fig. 2) is:

$Y=-0.016 X+7.734(r=-0.573, N=27, P<0.01)$.

In females there is a decrease in width from $6 \%$ to $5 \%$.

In $P$. phocoena the growth in height of the dorsal fin is isogonic in males and females at a level of about $7 \%$ of the total length. For males the mean is 6.93 (var. $=0.66$, S.D. $=0.81$, $N=29$ ); the mean for females is 6.77 (var. =
0.84, S.D. $=0.92, N=33$ ). The growth in length of the basis of the dorsal fin is isogonic in males and females. In males the mean length is $16.07 \%$ (var. $=4.94$, S.D. $=2.22, N=30$ ). In females the mean length of the basis of the dorsal fin is $15.27 \%$ (var. $=5.89$, S.D. $=2.43, N=$ 37). However, in both sexes a slight decrease of about $1 \%$ occurred during growth.

Summarizing the following can be concluded about growth in $P$. phocoena:

a. Growth in the anterior region of the body.

The results of the measurements taken along the animal's dorsal side reveal a difference in growth between males and females. In males the growth of the anterior part of the dorsum is negatively heterogonic. There is a decrease in relative length of about $6 \%$. In females the growth of this part is isogonic, the proportion stays constantly at about $62 \%$.

On the ventral side the growth of the anterior part of the body is negatively heterogonic in both sexes. In males the decrease in proportion is about $3 \%$, in females about $4 \%$.

Since in the anterior part of the body several reference points are available, the results of the measurements taken there can elucidate the results mentioned above. A first group of sizes concerns the head. Growth of the part of the head between the tip of the mandible and the centre of the eye is negatively heterogonic. In males there is a reduction of about $3 \%$, in females this reduction is about $4 \%$. Growth of the mandible (tip mandible to corner of mouth) is also negatively heterogonic, with a reduction of about $1 \%$ in males and about $2 \%$ in females. The growth of the part of the head between the centre of the eye and the orifice of the external auditory meatus is in males negatively heterogonic, and isogonic in females. However, in both sexes there is a slight reduction of about $1 \%$. The growth of the part of the head between the tip of the snout and the blowhole is negatively heterogonic in males and females, with a significant reduction of about $2 \%$ in both. So it can be concluded that during growth the head of $P$. phocoena shows a relative reduction in size.

The second group of measurements of the anterior part of the body concerns the neck region. 
The distance between the blowhole and the anterior end of the basis of the dorsal fin is measured. In this measurement the brain case is included, but constitutes only a small fraction of the entire measurement. Its change in size is small, as can be estimated from the measurements of the distance between the centre of the eye and the ear opening. In males and females of $P$. phocoena growth of the part between the blowhole and the anterior end of the basis of the dorsal fin is isogonic. In males there is a decrease in size of about $2 \%$. Together with the reduction of the size of the head, this results in negative heterogonic growth of the anterior part of the body at the dorsal side. In females, however, the part of the dorsum between the blowhole and the anterior end of the basis of the dorsal fin shows an increase of about $2 \%$. This seems to compensate partly the reduction of the size of the other parts in the anterior half of the body, resulting in isogonic growth in the front half of the body in females.

b. Growth in the posterior region of the body.

On the dorsal side of the posterior body region there is also a difference in growth between males and females. In males the growth is positively heterogonic. There is a significant increase of about $5 \%$ in the relative size of this part. In females the growth of this part is isogonic at a level of about $42 \%$ of the total length. In males the relative size of this part is slightly greater.

The growth on the ventral side of the body, between the umbilicus and the notch of the flukes is isogonic in both sexes, in males at a level of about $60 \%$ and in females at about $59 \%$ of the total length.

For the main body regions heterogonic growth is found in males of $P$. phocoena in the anterior and posterior part of the dorsal side and in the anterior part on the ventral side. In females only the anterior part on the ventral side shows negatively heterogonic growth, the growth in the other parts being isogonic. As both sides of the anterior part of the body of males show negatively heterogonic growth, there is a reduction in relative length of this part. This is an indication for a difference in shape of the body between males and females, which is accentuated by the increase of the poste- rior part of the dorsal side in males. The positively heterogonic growth in the posterior part at the dorsal side in males may be the result of either a relative change in the position of the dorsal fin or an increase in the height of the back above the level of the transverse processes of the spine in this part.

The growth of the part of the ventral body wall between the umbilicus and the anterior end of the genital slit is isogonic in both males and females of $P$. phocoena. In males this part is about $3.5 \%$ of the total length, while in females it is about $20 \%$.

The growth in length of the genital slit is isogonic in males. Its size is about $7 \%$ of the total length. In females on the contrary the growth of the genital slit is positively heterogonic. The increase in length is here about $2 \%$.

The part of the ventral body wall between the posterior end of the genital slit and the anus was only measured in males. Growth proves to be isogonic at a level of about $18 \%$ of the total length.

Growth of the part of the ventral side between the anus and the notch of the flukes proves to be isogonic in males and females. In both the length of this part is about $30 \%$ of the total length.

From the measurements of the flukes, flippers and the dorsal fin the following results are obtained. The growth of the span of the flukes is isogonic in males, the relative length is about $23 \%$ of the total length. In females the growth of this part is negatively heterogonic, with a decrease of about $3 \%$. Growth in length of the flippers is isogonic in both sexes, at a level of about $14 \%$ of the total length. Growth in width of the flippers is isogonic in males at about $5 \%$ or $6 \%$ of the total length. In females it is negatively heterogonic with a significant decrease of about $1 \%$. There seems to be a slight difference between males and females in the dimensions of the flippers and flukes.

Growth in height of the dorsal fin is isogonic in males and females at a level of about $7 \%$ of the total length. Growth in length of the basis of the dorsal fin is also isogonic in both sexes, in males at a level of about $16 \%$ of the total length and in females at a level of about $15 \%$. 


\section{Age analysis}

For the age analysis counts of the dentinal layers were made from longitudinal axial sections of the teeth of $P$. phocoena. Prior to sectioning the length and maximum diameter of each tooth was measured. For males the mean length of the teeth is $11.4 \mathrm{~mm}($ var. $=1.4$, S.D. $=1.2, N=19$, min. $=9.0 \mathrm{~mm}, \max .=12.8 \mathrm{~mm})$. The mean diameter is $2.4 \mathrm{~mm}$ (var. $=0.1, \mathrm{~S} . \mathrm{D}$. $=0.3$ ). In females the mean length of the teeth is $11.8 \mathrm{~mm}$ (var. $=1.7$, S.D. $=1.3, N=32$, min. $=8.6$ $\mathrm{mm}, \max .=14.4 \mathrm{~mm})$. The mean diameter of the teeth in females is $2.3 \mathrm{~mm}$ (var. $=0.1$, S.D. $=0.4$ ). From these data it is evident that in females the teeth reach a greater length than in males, while there is no difference in diameter in both sexes. The greater length of the teeth in females is most probably correlated with the greater total length attained by them, resulting in greater dimensions of the head.

The age analysis by means of teeth is based on the generally accepted assumption that one dentinal growth layer, composed of a relatively wide opaque zone and a relatively narrow translucent zone, is deposited each year. The terms opaque and translucent are applied when the sections of the teeth are viewed in transmitted light. In the material examined all teeth had open roots. The results of the counts are given in the appendix. From these data it is evident that the teeth reach their maximum length in the second or third year. As a consequence there is in $P$. phocoena no relation between the age and the length of the teeth. This is in contrast to the situation found in Kogia breviceps (De Blainville, 1838) during the first eight years of life. In this period the teeth of these animals increase in length (Van Bree, Van Utrecht \& Robson, in preparation). In Kogia the thickness of the growth layers in the dentine is fairly constant. They are deposited under an angle to the axis of the tooth, just as in the teeth of Physeter. In $P$. phocoena the growth layers are deposited more or less parallel to the axis of the tooth. This results in a gradual diminution of the pulp cavity. In the teeth of $P$. phocoena a decrease of the thickness of the successive growth layers is clear, as was demonstrated by Gaskin \& Blair

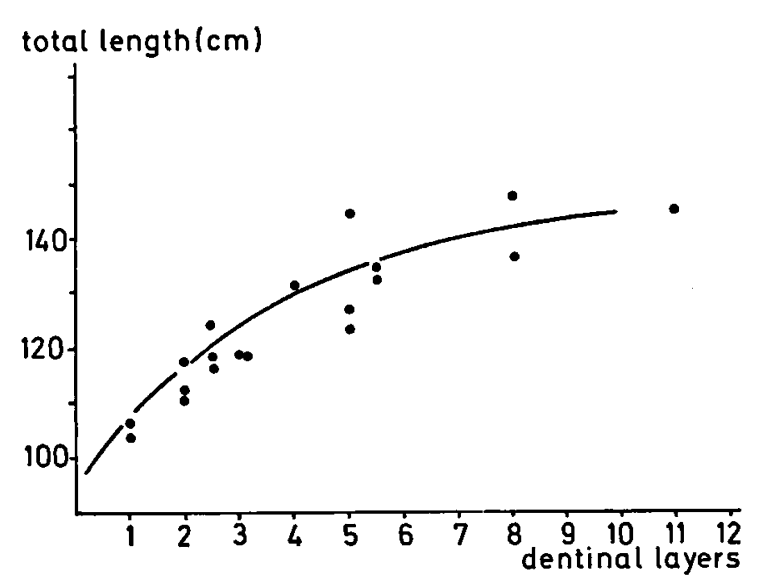

Fig. 3. Age-length relation in males of $P$. phocoena.

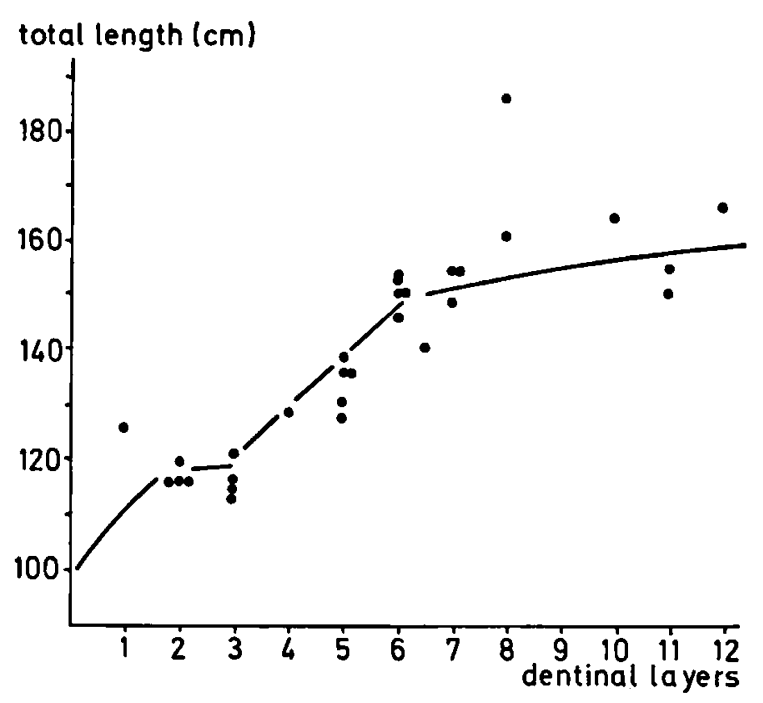

Fig. 4. Age-length relation in females of $P$. phocoena.

(1977) by means of statistical analysis of measurements.

In figs. 3 and 4 the relation between length and age is shown for males and females, respectively. It is clear that females attain a greater maximum length than males. In the present sample the maximum length found for females was $186 \mathrm{~cm}$, for males $151 \mathrm{~cm}$. The number of animals from which sufficient data as well as teeth were available is rather small for firm conclusions. However, some indications about growth in general and differences in growth between both sexes can be derived from the graphs. The growth curve for males shows a gradual increase in length from about $105 \mathrm{~cm}$ when one dentinal layer is deposited, 
to about $130 \mathrm{~cm}$ after the deposition of four layers. After that age the growth curve approaches an asymptote.

The growth curve for females in the present sample is quite different from that for males. Between the time of deposition of the first and fourth dentinal layer the animals attain a length of about $130 \mathrm{~cm}$. Thereafter there is a surge in the growth rate, in particular at the time between the deposition of the fifth and sixth dentinal layer. Then the curve also approaches an asymptote. In females this is about one year later than in males. These differences in growth may also explain the difference in maximum length attained by males and females. In the period of decreasing growth rate in males, females just show an increase. A length of about $150 \mathrm{~cm}$ is reached in the time that six layers are deposited in the dentine. Thereafter the growth rate also decreases. In the same time the males have reached a length of 130 to $135 \mathrm{~cm}$. These results are different from those obtained for $P$. phocoena from the western North Atlantic (Gaskin \& Blair, 1977). They found that in males and females the growth curve approaches an asymptote after four dentinal layers were deposited. However, females have a higher growth rate. These differences may be attributed to differences between the populations of the western and eastern North Atlantic. The growth curve for females of $P$. phocoena from the North Sea shows a rather unexpected course during the period in which the first three dentinal layers are deposited. Here the length in the successive age groups varies considerably and does not fit a normal curve. This is most probably due to the sampling method, and to the long period of time in which the sample was collected. The maximum number of dentinal layers found in the present sample is 12 (see appendix).

\section{Relation between body weight and length}

For 99 Harbour Porpoises (41 ô ô, 58 oq) from the North Sea, the regression of body weight (W) on standard length $(L)$ is calculated. The following equations are found:

$\log L=1.607+0.346 \log W$

for males, and

$\log L=1.609+0.347 \log W$

for females.

This illustrates the difference in size between males and females. Bryden (1972) calculated these relations for $P$. phocoena from the Baltic, using the data of Møhl-Hansen (1954), and found the following:

$\log L=1.552+0.357 \log W \quad$ for males, and $\log L=1.606+0.329 \log W \quad$ for females. Comparison of the regression equations for animals from the North Sea with those from the Baltic shows a slight difference in growth. This confirms earlier results (Van Utrecht, 1960) based on the comparison of data of 11 animals from the Baltic and 19 from the North Sea.

\section{Attainment of sexual maturity}

Sexual maturity was determined by analysing the testis weights and counting the scars and corpora lutea of ovaries. Histological examination of the testes was not accomplished because most animals were dead for at least about 24 hours before dissection or preservation could take place. This inevitably resulted in decomposition and uncertain results. In fig. 5 the percentage of testis weight is

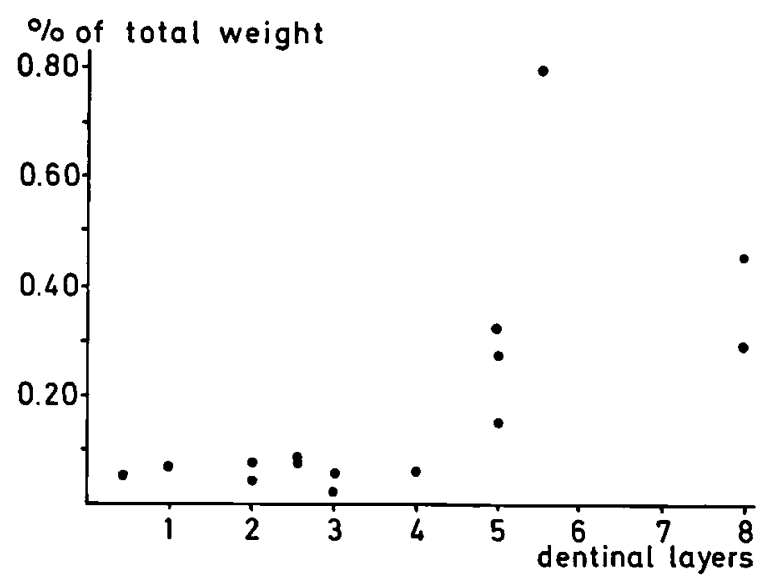

Fig. 5. Increase of testis weight in relation to age.

plotted against the number of dentinal layers. In the period in which up to four dentinal layers are formed the testis weights are all well below $0.10 \%$ of the body weight. In the period between the deposition of the fourth and fifth layer there is a steep increase in testis weight. Besides, there is a considerable variation in testis weights in older animals. This is most probably due to seasonal variations in testicular activity. The sudden strong increase in testis weight after the deposition of 
four dentinal layers is considered to be related to the attainment of sexual maturity. From the available data it can be concluded that males of $P$. phocoena from the North Sea are sexually mature at a body length of about $135 \mathrm{~cm}$, when five dentinal layers are deposited (see appendix).

In females, signs of ovulations like scars on the surface or protruding follicles or corpora lutea, are found predominantly in the left ovary. In all females having less than six dentinal layers, no signs of ovarian activity were found (see appendix). In animals with six or more dentinal layers, increasing numbers of scars were found on the ovaries. This leads to the conclusion that females of $P$. phocoena from the North Sea attain sexual maturity when six dentinal layers are deposited. On the average they have reached then a body length of about $150 \mathrm{~cm}$. Gaskin \& Blair (1977) found in the western North Atlantic sexually mature males with four dentinal layers and a length of about $140 \mathrm{~cm}$, and females with also four dentinal layers and a length of about $150 \mathrm{~cm}$.

Fisher \& Harrison (1970) concluded from their material, mainly from the western North Atlantic, that sexual maturity is reached at a length of about $133 \mathrm{~cm}$ in males and $145 \mathrm{~cm}$ in females. These figures for the body length at attainment of sexual maturity do not show large differences. The existing variations can be attributed to the method of sampling and the sample size. However, the age at which sexual maturity is attained differs considerably. This is at five and six years, respectively, for males and females from the North Sea, and at four years for the animals from Canadian waters. It seems that the growth rate in the population from the North Sea is lower than in the population from the western North Atlantic. The present results, as well as those from age analysis in baleen whales (Van Utrecht-Cock, 1966) and those from' age-growth analysis in eels (Deelder, 1976) seem to point to a more direct relation of the attainment of sexual maturity with length and growth rate in stead of with age.

\section{Moment of birth and duration of gestation}

In the sample of $P$. phocoena from the North Sea 10 very young animals varying in length from 67 to $90 \mathrm{~cm}$ were present (see appendix). All these animals, except those from August 1956 and September 1971, had still a small piece of umbilical cord attached. So these animals were born recently, and can be considered as neonates. Though their number is small some indications can be obtained.

All neonates were born in June of the various years, except one which was born in July. This indicates that the birth period in the North Sea has its peak in the month of June, which makes a gestation period of 11 months plausible when a short interval between two pregnancies is considered. In the present material the male neonates are slightly shorter than the females. This is confirmed by the observations of Verwey (1975). Fisher \& Harrison (1970) found that birth mainly occurs in June and July in Canadian waters. The neonates had a length varying from 80 to $90 \mathrm{~cm}$.

Perrin et al. (1977: 734, fig. 12) published a graph to illustrate the relation between length at birth $(\log X)$ and the length of the gestation period $(\log Y)$ for some species of odontocetes. They computed the regression line as:

$\log Y=0.4568 \log X+0.1659$.

Using this equation for the available data about

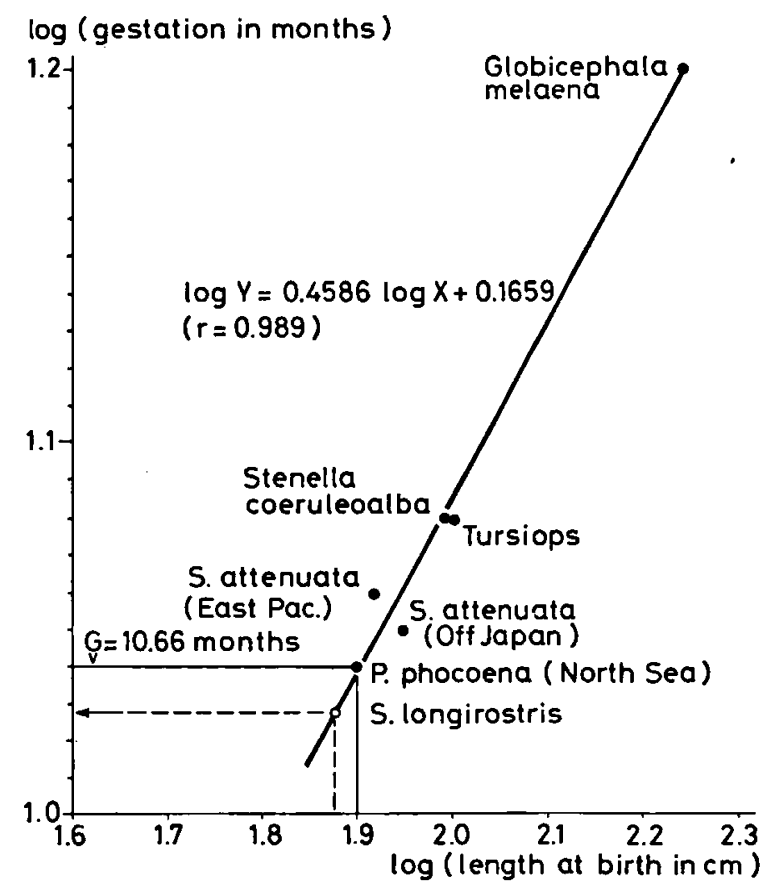

Fig. 6. Relationship between log length of gestation and $\log$ length at birth after Perrin et al. (1977: fig. 12) in which the data of $P$. pbocoena are included. 
the length at birth of $P$. phocoena from the North Sea, and an estimated gestation period of about 11 months, a point results which is very close to the calculated regression line (fig. 6).

\section{Weight of visceral organs}

The weights of the visceral organs expressed as a percentage of body weight are given in table I. A small portion of these data, viz. from 12 males and 16 females, all dissected before 1959, is already discussed by Slijper (1958).

Growth of the visceral organs is found to be isogonic in males and females of $P$. phocoena. This confirms Bryden's (1972) results. Calculations of the relationship between weight of the visceral organs and body weight for analysis of various growth coefficients, as done by Bryden (1972), have not been performed for the present material. This is not done because the autopsies showed that a considerable number of animals suffered from diseases some time before they were caught or stranded. This has also to be taken into consideration with respect to the figures in table I.

However, a few general remarks can be made. It is clear that there is a considerable individual variation in the weight of heart, lungs and liver. The mean weights of the various visceral organs

\section{TABLE I}

Weight of visceral organs of $P$. phocoena as percentage of total weight.

\begin{tabular}{|c|c|c|c|c|c|}
\hline & & $N$ & mean & variation & S.D. \\
\hline liver & $\hat{o} \hat{o}$ & 30 & 3.686 & 1.098 & 1.048 \\
\hline liver & 우 & 31 & 4.097 & 1.283 & 1.133 \\
\hline 1. kidney & $\hat{\delta} \hat{\theta}$ & 22 & 0.4395 & 0.007 & 0.083 \\
\hline r. kidney & $\hat{\delta} \hat{\delta}$ & 22 & 0.435 & 0.007 & 0.081 \\
\hline l. kidney & $9 \%$ & 26 & 0.492 & 0.081 & 0.0899 \\
\hline r. kidney & 우 웅 & 26 & 0.484 & 0.01 & 0.102 \\
\hline 1. adrenal & $\hat{\delta} \hat{\sigma}$ & 22 & 0.027 & 0.0001 & 0.0116 \\
\hline r. adrenal & ô $\hat{o}$ & 22 & 0.030 & 0.0002 & 0.013 \\
\hline 1. adrenal & $9 \%$ & 26 & 0.032 & 0.0001 & 0.0112 \\
\hline r. adrenal & 우 & 27 & 0.032 & 0.0001 & 0.0092 \\
\hline spleen & $\hat{o} \hat{\theta}$ & 29 & 0.022 & 0.0004 & 0.019 \\
\hline spleen & $9 \%$ & 28 & 0.025 & 0.0002 & 0.0121 \\
\hline pancreas & $\hat{\delta} \delta$ & 28 & 0.140 & 0.006 & 0.0787 \\
\hline pancreas & 우 우 & 30 & 0.176 & 0.002 & 0.0538 \\
\hline heart & $\hat{\delta} \hat{\delta}$ & 30 & 0.850 & 0.106 & 0.325 \\
\hline heart & $\$ 9$ & 32 & 0.956 & 0.223 & 0.472 \\
\hline 1. lung & ô $\hat{o}$ & 30 & 2.029 & 0.816 & 0.903 \\
\hline r. lung & $\hat{\delta} \hat{o}$ & 30 & 2.235 & 0.735 & 0.857 \\
\hline 1. lung & $9 \%$ & 33 & 2.190 & 0.549 & 0.741 \\
\hline r. lung & 웅 & 33 & 2.464 & 0.5797 & 0.761 \\
\hline
\end{tabular}

are greater in females than in males. In males and females the mean weights of the organs from the right half of the thorax and abdomen are greater than those of the corresponding organs from the left side, except for the kidneys. In males and females the left kidney was the heavier one. In one male the left kidney was missing. The weight of the right kidney in this animal was $0.953 \%$ of the body weight, which is about twice the mean weight for the right kidney of normal males. Probably the missing capacity of the left kidney was compensated in this way. In this animal the left and the right adrenal glands were present in their normal position.

\section{SUMMARY}

Analysis of the measurements of various parts of the body of $P$. phocoena from the North Sea, ranging from 106 to $186 \mathrm{~cm}$ in body length, revealed sexual dimorphism in some parts. The maximum body length for males was $151 \mathrm{~cm}$, and for females $186 \mathrm{~cm}$. In males the relative length of the anterior part of the dorsum decreases during growth while it increases in the posterior part. In females there is no change in proportion in both parts. In males and females the relative length of the head decreases. Only in females the part of the dorsum between the blowhole and the anterior end of the basis of the dorsal fin shows an increase, compensating at least partly the proportional decrease of the head. In females this results in isogonic growth of the dorso-anterior part. In males and females the relative length of the part of the ventral side of the body, between the tip of the mandible and the umbilicus, decreases in proportion, while there is no change in the part between the umbilicus and the notch of the flukes. Sexual dimorphism was found in the greater length of the genital slit, the more slender flippers and the smaller proportion of the span of the flukes in females.

According to the age-length relationship, females have a somewhat higher growth rate than males. Sexual maturity in males is attained in the fifth year, and in females in the sixth year, at lengths of about $135 \mathrm{~cm}$ and $150 \mathrm{~cm}$, respectively. The lengths at the attainment of sexual maturity of $P$. phocoena from the North Sea do not differ 
much from those known from other populations of this species. However, the growth rates are different in the various populations. The age data suggest a lower growth rate in the North Sea population than e.g. in the population from Canadian waters.

Based on the available data of neonates, the peak birth period for the population of $P$. phocoena from the North Sea is in June, while the estimated gestation period is about eleven months. The length at birth varies from $67 \mathrm{~cm}$ to $80 \mathrm{~cm}$. The female neonates are slightly longer than the males.

The mean weights of the visceral organs as a percentage of the body weight, are found to be higher in females. A higher mean weight of the visceral organs of the right half of the body is found. The reverse is found for the kidneys.

\section{ACKNOWLEDGEMENTS}

The material for the present study became available through the cooperation of various institutes and of a great number of people. In this respect the Netherlands Institute of Sea Research, Texel, and the Netherlands Institute for Fishery Investigations, IJmuiden, are specially mentioned. The author is indebted to the Institute of Taxonomic Zoology (Zoölogisch Museum) of the University of Amsterdam, Mammals Department, Curator Dr. P. J. H. van Bree, for providing part of the material, and in particular to Mr. P. Borgman and Mr. G. Verlaan of the same institute, who assisted during nearly all the dissections throughout the years. The cooperation of my wife Dr. C. N. van Utrecht-Cock and of Dr. E. J. Schenkkan, who are likewise interested in cetaceans, was of great value.

\section{REFERENCES}

BRYDEN, M. M., 1972. Growth and development of marine mammals. In: R. J. HARRISON ed., Functional anatomy of marine mammals, 1: 1-79 (Academic Press, London/ New York).

Bree, P. J. H. van \& A. M. Husson, 1974. Strandingen van Cetacea op de Nederlandse kust in 1972 en 1973. Lutra, 16: $1-10$.
DeElder, C. L., 1976. Veranderingen in het groeipatroon van IJsselmeeraal. Visserij, 6: 403-406.

Fisher, H. D. \& R. J. HARrison, 1970. Reproduction in the Common Porpoise (Phocoena phocoena) of the North Atlantic. J. Zool., 161: 471-486.

GAskin, D. E. \& B. A. BlaIR, 1977. Age determination of Harbour Porpoise, Phocoena phocoena (L.), in the western North Atlantic. Can. J. Zool., 55 (1): 18-30.

Husson, A. M. \& P. J. H. van BREE, 1972. Strandingen van Cetacea op de Nederlandse kust in 1970 en 1971. Lutra, 14: $1-6$.

- \& - 1976. Strandingen van Cetacea op de Nederlandse kust in 1974 en 1975. Lutra, 18: 25-32.

MrtChell, E. D. (special editor), 1975. Report of the Meeting on Smaller Cetaceans. Montreal, April 1-11, 1974. J. Fish. Res. Bd. Can., 32 (7): 889-983.

MøHL-HANSEN, U., 1954. Investigations on reproduction and growth of the porpoise (Phocaena phocaena (L.)) from the Baltic. Vidensk. Meddr. dansk naturh. Foren., 116: 369-396.

Nielsen, H. G., 1972. Age determination of the Harbour Porpoise, Phocoena phocoena (L.) (Cetacea). Vidensk. Meddr. dansk naturh. Foren., 135: 61-84.

Perrin, W. F., D. B. Holts \& R. B. Miller, 1977. Growth and reproduction of the Eastern Spinner Dolphin, a geographical form of Stenella longirostris in the eastern tropical Pacific. Fish. Bull., 75 (4): 725-750.

SLIJPER, E. J., 1958. Organ weights and symmetry problems in porpoises and seals. Archs. néetl. Zool., 13 (suppl. 1): $97-113$.

$\longrightarrow$, 1962. Whales: 1-475 (Hutchinson, London).

Utrecht, W. L. vaN, 1960. Einige Notizen über Gewicht und Länge von Schweinswalen (Phocaena phocaena) aus der Nord- und Ostsee. Säugetierk. Mitt., 8 (3/4): 142-144.

- 1969. A remarkable feature in the dentine of teeth of odontocetes. Beaufortia, 16: 157-162.

UTRECHT-CoCK, C. N. VAN, 1966. Age determination and reproduction of female fin whales, Balaenoptera physalus (Linnaeus, 1758) with special regard to baleen plates and ovaries. Bijdr. Dierk., 35: 39-100.

Utrecht, W. L. vaN \& A. M. Husson, 1968. Strandingen van Cetacea in het voorjaar van 1967 op de Nederlandse kusten. Lutra, 10: 7-17.

Verwey, J., 1975. The cetaceans Phocoena phocoena and Tursiops truncatus in the Marsdiep area (Dutch Waddensea) in the years 1931-1973. Ned. Inst. Onderz. Zee, Publties Versl., $17(\mathrm{a} / \mathrm{b})$ : 1-153. 
APPENDIX

List of animals examined in the present study (for legends, vide infra)

के oิ

ZMA coll. no.

\begin{tabular}{|c|c|c|}
\hline 8.166 & (WO & 70) \\
\hline 10.724 & (WO & 88) \\
\hline 8.651 & (WO & 72) \\
\hline 2.643 & (WO & 45) \\
\hline \multicolumn{3}{|l|}{16.872} \\
\hline 9.203 & (WO & 76) \\
\hline \multicolumn{3}{|l|}{2.907} \\
\hline 16.372 & (WO & 163) \\
\hline 12.983 & (WO & 94) \\
\hline 13.138 & (WO & 95) \\
\hline 13.836 & (WO & 102) \\
\hline \multicolumn{3}{|l|}{16.871} \\
\hline 14.292 & (WO & 110) \\
\hline 16.348 & (WO & 160) \\
\hline 10.631 & (WO & 87) \\
\hline 15.390 & (WO & 138) \\
\hline 7.623 & (WO & 67) \\
\hline 13.834 & (WO & 100) \\
\hline \multicolumn{3}{|l|}{18.011} \\
\hline 4.193 & & \\
\hline
\end{tabular}

(WO 1a)

(WO 3)

(WO 7)

(WO 8)

(WO 10)

(WO 17)

(WO 40)

(WO 44)

(WO 50)

(WO 51)

(WO 52)

4.140 (WO 55)

6.131 (WO 56)

7.559 (WO 63)

7.960 (WO 64) (WO 75)

14.337 (WO 108)

14.517 (WO 119)

(WO 128)

18.362

18.122

16.108 (WO 157)

(WO 135)

우

\begin{tabular}{|c|c|c|c|c|c|c|}
\hline 8.716 & (WO & 74) & 126 & 25.4 & 10.21 & 2.42 \\
\hline 8.474 & & & 127 & 23 & 10.53 & 2.00 \\
\hline 8.167 & (WO & 71) & 120 & 26 & 13.16 & 2.42 \\
\hline 6.065 & (WO & 61) & 116.5 & 20 & 10.53 & 2.74 \\
\hline 3.050 & & & 116.5 & - & 8.63 & 2.00 \\
\hline 15.668 & (WO & 148) & 116.5 & 25 & 9.47 & 2.00 \\
\hline 16.106 & (WO & 159) & 121.5 & 21.5 & - & - \\
\hline 17.736 & & & 116.5 & - & - & - \\
\hline 13.538 & & & 113 & - & 11.37 & 2.21 \\
\hline 15.095 & (WO & 130) & 115 & 23.5 & 12.21 & 1.79 \\
\hline 16.107 & (WO & 158) & 129 & 28.5 & 10.84 & 2.00 \\
\hline 16.362 & (WO & 162) & 131 & 31.5 & - & - \\
\hline
\end{tabular}
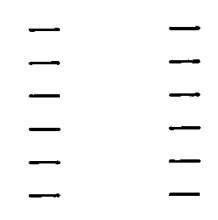

teeth

\begin{tabular}{lccc}
\cline { 3 - 4 } $\begin{array}{ll}\text { length } \\
(\mathrm{cm})\end{array}$ & $\begin{array}{c}\text { weight } \\
(\mathrm{kg})\end{array}$ & $\begin{array}{c}\text { length } \\
(\mathrm{mm})\end{array}$ & $\begin{array}{l}\text { diam. } \\
(\mathrm{mm})\end{array}$
\end{tabular}

106

103
110

18.5
18

12.00

2.60

18.5

11.05

112

117

124

118

116

118

118

131

123
126.5

$144 \quad 32$

$132 \quad 36.2$

134

147

136

145

146
142

142
121

121
71

139

75.5

67

129

105
136

115
144

144

146

140

112.5

116
151

149

136.5

146.5

126
113

23

21

24

30

22.6

17.1
17

25.5

23

28

36.2
37

48

$$
31
$$

40.5

- 44.3

26.5

6
40.5

$$
\begin{aligned}
& 8 \\
& 5.5
\end{aligned}
$$

19

23.5
37

22

22
37

49

30

17

24.5
36

42

34.5

32.5

12

89

20.6

12.53

12.84

11.68

9.58

9.05

12.32

10.00

10.32

11.89

11.79

12.21

10.53

-

10.00

12.32

12.53

2.63

2.42

2.74

2.32

2.74

2.11

1.89

2.11

1.79

2.21

2.11

2.74

2.32

2.63

2.84

2.00

2.63

- -

$\overline{\bar{Z}}$

$\overline{=}$

$\bar{z}$

$\bar{z}=$

$\overline{\bar{z}}$

$\bar{\Xi}$

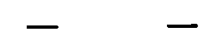

$\bar{z}$

$\overline{\bar{z}}$

.42

2.00

2.74

2.00

2.21

1.79

$-$
$\%$ testis weight

0.067

$\overline{0.073}$

0.04

0.079

$\overline{0.086}$

0.02

0.056

0.06

$0 . \overline{148}$

0.267

0.781

0.319

0.295

0.455

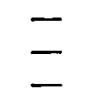

age

sampled

VI $\quad-1956$

VII -1967

VII -1965

IV -1959

VII -1974

VII -1966

IX -1960

XII -1973

I $\quad-1960$

I $\quad-1960$

XI $\quad-1970$

VII -1974

III -1971

XI -1973

IX $\quad .1967$

XI -1972

III -1963

XI -1970

IX -1975

V $\quad-1961$

I $\quad-1955$

$\begin{array}{llll}- & - & \text { VIII } & -1955 \\ - & \text { neon. } & \text { VI } & -1957\end{array}$

$\begin{array}{lllll}- & - & \text { IX } & -1957\end{array}$

- neon. VI -1957

- neon. VII -1957

$\begin{array}{llll}- & - & \text { IV } & -1958 \\ - & - & \text { III } & -1959\end{array}$

- $\quad$ - XII $\quad-1960$

- $\quad$ - $\quad$ II $\quad-1961$

- $\quad$ - III -1961

$\begin{array}{llll}- & - & \text { IV } & -1961 \\ - & \text { neon. } & \text { VI } & -1961\end{array}$

- $\quad$ - $\quad$ III $\quad-1963$

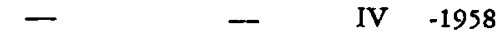

$\begin{array}{llll}-\overline{6} 61 & - & X I & -1970\end{array}$

$\begin{array}{lllll}0.892 & - & \text { VII } & -1971\end{array}$

- $\quad$ - XII -1971

$0.689 \quad-\quad$ VIII -1975

- $\quad$ - I I $\quad$ I

$\begin{array}{lllll}0.049 & \text { - } & \text { X } & -1973 \\ 0.05 & - & \text { IX } & -1971\end{array}$

ovaries

juv.

juv.

juv.

juv.

juv.

juv.

juv.

juv.

juv.

juv.

juv.

VII -1965

VIII -1965

V -1965

IX -1963

II -1973

X -1973

IV -1975

X -1970

III -1972

X -1973

XI -1973 


\begin{tabular}{|c|c|c|c|c|c|c|c|c|c|c|}
\hline \multirow{2}{*}{\multicolumn{3}{|c|}{ ZMA coll. no. }} & \multirow[b]{2}{*}{$\begin{array}{l}\text { length } \\
(\mathrm{cm})\end{array}$} & \multirow[b]{2}{*}{$\begin{array}{c}\text { weight } \\
(\mathrm{kg})\end{array}$} & \multicolumn{2}{|c|}{ teeth } & \multirow[b]{2}{*}{ ovaries } & \multirow[b]{2}{*}{ age } & \multirow{2}{*}{\multicolumn{2}{|c|}{ sampled }} \\
\hline & & & & & $\begin{array}{l}\text { length } \\
(\mathrm{mm})\end{array}$ & $\begin{array}{l}\text { diam. } \\
(\mathrm{mm})\end{array}$ & & & & \\
\hline \multicolumn{3}{|l|}{18.123} & 128 & 33 & 11.47 & 2.00 & juv. & 5 & I & -1976 \\
\hline \multicolumn{3}{|l|}{15.921} & 136 & 19.5 & 12.00 & 1.79 & juv. & 5 & IV & -1973 \\
\hline 16.371 & (WO & 164) & 138 & 26.4 & 11.89 & 2.21 & juv. & 5 & XII & -1973 \\
\hline 14.336 & (WO & 109) & 130 & 35.5 & 12.11 & 2.11 & juv. & 5 & XI & -1970 \\
\hline \multicolumn{3}{|l|}{18.124} & 136 & 31 & 12.21 & 2.11 & juv. & 5 & XII & -1975 \\
\hline \multicolumn{3}{|l|}{18.125} & 137.5 & 32 & 10.04 & 2.11 & juv. & 5 & XII & -1975 \\
\hline 13.413 & (WO & 99) & 154 & 41.1 & 13.79 & 2.74 & 5 scars & 6 & VII & -1970 \\
\hline 13.247 & (WO & 98) & 153 & 39.2 & 13.79 & 2.21 & sex. mat. & 6 & III & -1970 \\
\hline 11.650 & (Wo & 92) & 146.5 & 43.5 & 11.79 & 2.63 & $1 \mathrm{c} ; 1 \mathrm{f}$ & 6 & VII & -1967 \\
\hline 2.644 & (WO & 48) & 151 & 43.5 & 11.47 & 2.21 & sex. mat. & 6 & I & -1960 \\
\hline \multicolumn{3}{|l|}{18.032} & 150 & 49 & 11.89 & 2.00 & $11 \mathrm{f} ; 1$ scar & 6 & IX & -1975 \\
\hline \multicolumn{3}{|l|}{18.103} & 141 & 28 & 10.53 & 2.11 & - & $6-7$ & $\mathbf{X}$ & -1975 \\
\hline 2.582 & (WO & 46) & 155 & 46 & 11.89 & 2.63 & scars & 7 & IV & -1959 \\
\hline \multicolumn{3}{|l|}{2.906} & - & - & 11.16 & 2.32 & - & 7 & - & - \\
\hline 15.163 & (WO & 133) & 155 & 46 & 10.95 & 1.89 & 10 scars & 7 & IV & -1972 \\
\hline \multicolumn{3}{|l|}{18.033} & 149 & 33 & 12.21 & 2.53 & - & 7 & $\mathbf{X}$ & -1975 \\
\hline \multirow{2}{*}{\multicolumn{3}{|c|}{$\begin{array}{r}16.363 \\
2.905\end{array}$}} & 161.5 & 52.6 & - & - & 3 scars & 8 & XII & -1973 \\
\hline & & & 186 & 85 & 12.63 & 2.74 & - & 8 & VIII & -1960 \\
\hline $\begin{array}{l}2.905 \\
4.794\end{array}$ & (WO & 57) & 164 & 68 & 12.21 & 2.95 & pregn. & 10 & VI & $\left.-1961^{1}\right)$ \\
\hline 2.581 & (WO & 42) & 155 & 41 & 13.47 & 2.95 & lact. & 11 & V & -1962 \\
\hline 8.041 & (WO & 69) & 151 & 41 & 14.42 & 2.84 & 1 c; scars & 11 & $\mathbf{V}$ & -1962 \\
\hline 18.156 & & & 166.5 & 49.5 & 11.79 & 2.32 & scars & 12 & I & .1976 \\
\hline & (WO & 1) & 142 & 46 & - & - & $1 \mathrm{c}$; scars & - & II & $\left.-1955^{2}\right)$ \\
\hline & (WO & 4) & 160 & 60.5 & - & 一 & sex. mat. & 一 & VII & .1955 \\
\hline & (WO & 4a) & 79 & 6.5 & - & - & - & neon. & NO 4 & \\
\hline & (WO & 6) & 118 & 21.5 & - & - & juv. & - & IX & -1956 \\
\hline & (WO & 9) & 80 & 7 & - & 一 & - & neon. & VI & -1957 \\
\hline & (WO & 9a) & 77 & 7 & - & - & - & neon. & VI & -1957 \\
\hline & (WO & 15) & 143 & 42 & - & - & scars & - & VI & -1956 \\
\hline & (WO & 16) & 86 & 10 & - & 一 & juv. & - & VIII & -1956 \\
\hline & (WO & 22) & 160.5 & 50 & - & - & sex. mat. & - & IX & -1957 \\
\hline & (WO & 31) & 160 & 50.5 & - & - & pregn. & - & I & $-1958^{3}$ ) \\
\hline & (wo & 32) & 115 & 23.6 & - & - & juv. & - & I & -1958 \\
\hline & (WO & 41) & 147 & 55 & - & - & $1 \mathrm{c}$; scars & - & IX & .1958 \\
\hline Data fro & NIO & & 145 & 38 & - & - & - & - & III & .1960 \\
\hline Data fro & m NIO & & 74 & 6.3 & - & $\longrightarrow$ & - & neon. & VI & -1959 \\
\hline Data fro & $\mathrm{m} \mathrm{NIO}$ & & 128 & 20.6 & - & - & - & - & VIII & .1960 \\
\hline & (WO & 53) & 134.5 & 35 & - & - & - & - & I & .1960 \\
\hline 4.139 & (WO & 54) & 139 & 31.5 & - & - & - & - & XI & -1960 \\
\hline & (WO & 58) & 120 & 23.5 & - & - & juv. & - & VI & -1962 \\
\hline & (WO & 59) & 152 & 37 & - & - & - & - & $\mathrm{V}$ & .1962 \\
\hline & (WO & 62) & 158 & 45 & - & - & - & - & IX & -1962 \\
\hline 7.560 & (WO & 65) & 151 & 46 & - & - & sex. mat. & - & IV & -1962 \\
\hline 7.839 & (WO & 68) & 128 & 26.2 & - & - & - & - & XI & -1964 \\
\hline & & & 125 & 28 & - & - & juv. & - & IV & -1969 \\
\hline & (WO & 78) & 103 & 18 & - & - & juv. & - & VII & -1967 \\
\hline 13.835 & (WO & 102) & 124 & 21 & - & - & juv. & - & XI & -1970 \\
\hline 21.738 & (WO & 123) & 158 & 45 & - & - & 11 scars & - & VIII & $\left.-1971^{4}\right)$ \\
\hline 15.391 & (WO & 139) & 155 & 41 & - & - & 10 scars & - & III & -1972 \\
\hline 15.625 & (WO & 147) & 112 & 23 & - & - & juv. & - & VIII & -1972 \\
\hline 2.643 & (WO & 49) & 112 & 23 & 一 & - & - & - & II & .1959 \\
\hline
\end{tabular}

1) foetus, $9,86 \mathrm{~cm}, 10 \mathrm{~kg} ;{ }^{2}$ ) foetus, $35 \mathrm{~cm} ;{ }^{3}$ ) foetus, $\hat{\delta}, 35.5 \mathrm{~cm} ;{ }^{4}$ ) animal in the collections of Rijksmuseum van Natuurlijke Historie, Leiden.

$c=$ corpus luteum or corpus albicans; $f=$ follicle; lact. = lactating; neon. = neonatus; pregn. = pregnant; scars = scars of ovulations visible at the surface of the ovary; sex, mat. = sexually mature.

NIOZ = Nederlands Instituut voor Onderzoek der Zee, Netherlands Institute of Sea Research.

WO $=$ Walvis Onderzoek, formerly in the Zoological Laboratory, University of Amsterdam.

ZMA = Zoölogisch Museum, Amsterdam. 